\title{
Vídeo Educativo Como Estratégia Para Acolhimento de Familiares de Recém-Nascidos Internados em Utin
}

\author{
Aline Baldissera Leal, ${ }^{1}$ Taís Fim Alberti, ${ }^{2}$ Andrea Ad Reginatto ${ }^{2}$
}

\section{RESUMO}

O estudo teve como objetivo geral desenvolver uma tecnologia educativa que viesse a contribuir com orientações de enfermagem para familiares de recém-nascidos (RNs) internados. Estudo de caso descritivo e de natureza qualitativa foi desenvolvido na Unidade de Terapia Intensiva Neonatal (Utin) do Hospital Universitário de Santa Maria (HUSM). A coleta de dados foi realizada, em um primeiro momento, por meio de questionário com as enfermeiras da Utin e, em seguida, mediante entrevista com as mães dos RNs. A partir dos dados coletados, foi construído um vídeo educativo, seguindo a metodologia de Filatro (2008). Após, ele foi submetido a um processo de avaliação/validação pelo Núcleo de Educação Permanente em Saúde (Neps) e pelas enfermeiras da Utin do hospital em questão. O processo incluiu reuniões do Neps e entrevista gravada com as enfermeiras, agrupando-se as falas em duas categorias: Conteúdo, aspectos técnico-estéticos e proposta pedagógica do vídeo educativo, e Tecnologia educativa como ferramenta na Educação em Saúde de familiares. Os grupos avaliadores concordaram que o vídeo continha todas as informações necessárias e fizeram sugestões para melhoria, as quais foram incluídas na edição final. Conclui-se, com o vídeo validado, que ele possui qualidade para ser utilizado com o público-alvo em sala de espera, constituindo, assim, um material de uso institucional, que possibilitará uma melhor compreensão dos familiares em relação à hospitalização. Além disso, a pesquisa desenvolvida pode apontar um método para o desenvolvimento de outros materiais, mediados pelas tecnologias, visando à humanização no acolhimento em instituições de saúde.

Palavras-chave: tecnologias educacionais; educação em saúde; enfermagem neonatal; recém-nascidos; pais.

\section{EDUCATIONAL VIDEO WITH STRATEGY TO RECEPTION THE RELATIVES OF HOSPITALIZED NEWBORN AT UTIN}

\section{ABSTRACT}

The study aimed to develop an educational technology that would contribute with nursing guidelines for hospitalized newborn family members (NBs). Descriptive and qualitative case study, developed at the Neonatal Intensive Care Unit (Utin) of the Santa Maria University Hospital (HUSM). Data collection was carried out first through a questionnaire with nurses from the Utin and then through interviews with the mothers of the newborns. From the data collected, an educational video was built, following the methodology of Filatro (2008). Afterwards, he was submitted to an evaluation / validation process by the Center for Permanent Education in Health (Neps) and by nurses of the Utin of the hospital in question. The process included Neps meeting and recorded interviews with the nurses, grouping the speeches into two thematic groups: Content, technical-aesthetic aspects and pedagogical proposal of the educational video and Educational technology as a tool in the Health Education of family members. The evaluators agreed that the video contained all the necessary information and suggestions for improvement, such as which were accepted and included in the final edition. It is concluded, with the validated video, that it has quality to be used with the target audience in the waiting room, leaving a material for institutional use, that will enable a better understanding in relation to hospitalization. In addition, a developed research can point to a method for the development of others materials, mediated by technologies, specifying the humanization in the reception in health institutions.

Keywords: educational technologies; health education; neonatal nursing; newborns; parentes.

RECEBIDO EM: 29/10/2020

MODIFICAÇÕES SOLICITADAS EM: 18/1/2021

ACEITO EM: 26/2/2021

\footnotetext{
${ }^{1}$ Autora correspondente. Universidade Federal de Santa Maria - UFSM. Av. Roraima no 1000 - Cidade Universitária, Bairro Camobi, Santa Maria/RS, Brasil. CEP 97105-900. http://lattes.cnpq.br/5220311204787824. http://orcid.org/0000-00025124-8554. baldisseraaline83@gmail.com

2 Universidade Federal de Santa Maria - UFSM. Santa Maria/RS, Brasil.
} 


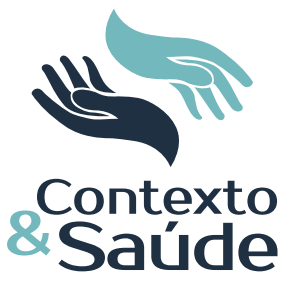

\section{INTRODUÇÃO}

O enfermeiro possui conhecimento para desenvolver estratégias de ensino na gestão dos cuidados de enfermagem que concorram para a instituição de novos recursos tecnológicos para os pacientes. Assim, as instituições buscam a presença de enfermeiros cada vez mais aptos a utilizar as tecnologias de informação e comunicação (TICS), a fim de melhorar o processo de cuidado do paciente e da família e criar processos educativos inovadores (LANDEIRO et al., 2015).

Neste sentido, na área da saúde, por meio das tecnologias, o enfermeiro consegue organizar e planejar melhor as suas atividades assistenciais, gerenciais e educacionais, buscando a qualidade da assistência prestada ao cliente. Desta forma, dentro desse contexto, as Tecnologias Educativas (TE) são estratégias relevantes para a realização da Educação em Saúde e para o processo de ensino-aprendizagem em diversas áreas, com destaque para a neonatologia, que é o ramo da pediatria que compreende crianças do nascimento até 28 dias de vida.

A Educação em Saúde é uma das principais funções do profissional enfermeiro e uma área de atuação em que se pode usar da criatividade e da inovação. Os espaços para a realização dessa prática educativa permitem tirar dúvidas e ter contato com novos conhecimentos, promovendo um aprendizado que contribui para tornar as pessoas mais preparadas para lidar com acontecimentos e situações que fazem parte da vida e se relacionam com a saúde (SOUZA et al., 2013).

Observa-se que, na área neonatal, existe um grande desafio para o profissional enfermeiro e toda a equipe, isto porque o cuidado não é somente para o neonato, mas é direcionado também ao acolhimento dos familiares. Como mediador entre a equipe de enfermagem e a família, o enfermeiro precisa compreender os problemas e as necessidades dos pais, a fim de desenvolver um plano de cuidados efetivo para os Recém-Nascidos (RNs) e seus genitores (SOUSA et al., 2017).

Desse modo, as tecnologias educativas podem melhorar a qualidade do cuidado prestado aos familiares de pacientes internados na Utin, fortalecendo a humanização e o vínculo entre pais e filhos e pais e equipe de enfermagem. Nesse contexto, a qualidade do cuidado depende da competência técnica do profissional e também da habilidade dele em interagir com a família, sendo de grande relevância o diálogo no processo da hospitalização; isso porque o período neonatal é um momento de grande vulnerabilidade na vida desses RNs. Dessa forma, estes, e suas famílias, necessitam de cuidados especiais. Quanto maior o número de complicações que podem agravar o estado de saúde do bebê, maior é o tempo de internação, favorecendo o aumento do risco de mortalidade e morbidade (FREITAS et al., 2018).

O momento mais esperado pela família é o nascimento do bebê e a ida com ele para casa. Quando isso não acontece, contudo, em razão de uma internação, por exemplo, ocorre uma separação brusca entre os pais e o filho. Nesse momento são desencadeados sentimentos e sensações, como angústia e ansiedade, que prejudicam a interação entre ambos. Consequentemente, isso gera estresse e insegurança por parte dos pais em relação à equipe de atendimento que atua no local. 
$\mathrm{O}$ acolhimento que o enfermeiro realiza com esses familiares logo após a internação do RN, e as trocas de informações que acontecem durante as visitas no dia a dia, ainda não parecem suficientes para que esses pais se sintam mais seguros diante da hospitalização. Dessa forma, a comunicação entre equipe de saúde e família deve ser satisfatória a fim de gerar um bom relacionamento, pois a falta de informações provoca ansiedade e o fornecimento destas permite o melhor enfrentamento das situações vivenciadas.

Durante vivência na Unidade de Terapia Intensiva Neonatal (Utin) do Hospital Universitário de Santa Maria (HUSM), observou-se a aflição e a angústia dos pais com o seu bebê internado na unidade desde o momento da internação até a alta hospitalar. Assim, conforme Souza et al. (2013), pode-se afirmar que o trabalho educativo com pacientes e familiares não é uma tarefa simples, uma vez que não se limita à transmissão de informações; é uma prática compartilhada, de troca de saberes.

Sombrio e Ulbricht (2015) salientam que o mundo do trabalho procura por profissionais que não sejam apenas especialistas em um determinado conteúdo, mas que sejam criativos, inovadores e líderes. Assim, na Utin existem muitas possibilidades para se trabalhar com os pais, desde todo o funcionamento do setor, os cuidados rotineiros com o filho, os horários de visita, entre outros.

Em vista disso, o problema norteador desta pesquisa enfatiza o seguinte questionamento: Um material educativo, mediado pelas tecnologias educativas, possibilita melhorar a compreensão dos familiares em relação à hospitalização de seus RNs internados na Utin?

A partir da questão, o objetivo geral da pesquisa foi desenvolver uma tecnologia educativa para contribuir com orientações de enfermagem para os familiares dos RNs internados.

A introdução desta proposta no contexto hospitalar, especialmente no setor de neonatologia, será de grande relevância e apresenta caráter inovador, pois permitirá a construção de conhecimento, cuidados e afetos, promovendo uma assistência acolhedora entre a equipe e os familiares, transformando o ambiente de uma Utin, que gera angústia, medo, tristeza, insegurança, em um cenário capaz de inspirar esperança, conforto e bem-estar aos pais, facilitando o enfrentamento dessa nova rotina e situação vivenciada pela internação do RN.

\section{MÉTODO}

A presente investigação foi desenvolvida por meio de uma pesquisa descritiva, do tipo estudo de caso, com análise de dados de natureza qualitativa. A pesquisa foi desenvolvida no HUSM, localizado na região central do Estado do Rio Grande do Sul, sendo um dos únicos hospitais da região que atende pelo Sistema Único de Saúde (SUS). O cenário escolhido para o desenvolvimento do estudo foi a UTIN.

Para o desenvolvimento da pesquisa os procedimentos metodológicos foram agrupados em quatro etapas. Na primeira etapa realizaram-se estudos e 
pesquisas bibliográficas referentes ao contexto da pesquisa, buscando, na literatura, o que vinha sendo produzido em relação à temática abordada.

Na segunda etapa, após a aprovação do projeto pelo Comitê de Ética em Pesquisa (CEP) da Universidade Federal de Santa Maria (UFSM), sob o parecer no 3.257.604, foi iniciada a coleta de dados para identificar as necessidades de orientação/informação dos profissionais enfermeiros, pacientes e familiares referentes à unidade neonatal. Nessa etapa a coleta de dados foi realizada com dois grupos de participantes: 1) enfermeiros da unidade, cujo critério de inclusão foi a experiência de três anos no setor; e 2) familiares (pai ou mãe) dos pacientes internados. A coleta de dados foi realizada por uma amostragem por saturação dos dados (FONTANELLA; RICAS; TURATO, 2008).

Dos 21 profissionais enfermeiros que prestavam assistência de enfermagem no cenário do estudo no momento dessa etapa, houve a participação de 15, todas do sexo feminino. Em relação aos familiares, resultou em uma amostra de 15 mães. Para manter o anonimato das enfermeiras e das mães, elas foram identificadas com 3 letras seguidas de um algarismo numérico para representar a ordem de participação, por exemplo: ENF 1 (Enfermeira 1) e MÃE 1 (Mãe 1).

Inicialmente as enfermeiras responderam a um questionário semiestruturado com questões abertas e fechadas. Na sequência, as mães participaram de uma entrevista gravada, seguindo um roteiro. Todas as participantes assinaram o Termo de Consentimento Livre e Esclarecido (TCLE). Foram identificadas as necessidades das mesmas e, após todo o material ser explorado, foram organizadas as respostas, identificando as unidades de análise comuns. Os dados que emergiram dessa parte do estudo foram analisados conforme a análise temática proposta por Bardin (2016), por meio de categorias.

$\mathrm{Na}$ terceira etapa foi desenvolvido o vídeo educativo, seguindo-se a metodologia de Filatro (2008), que é o design instrucional, por meio do modelo ADDIE, que se divide nas fases de análise, desenho, desenvolvimento, implementação e avaliação.

$\mathrm{Na}$ fase de análise foram levantadas as necessidades de informação e de conhecimento das participantes da pesquisa por meio da observação dos dados coletados pelo questionário e pela entrevista. $\mathrm{Na}$ fase de desenho foi planejada e desenhada uma primeira ideia do conteúdo que seria abordado, pensando nas cenas, nas falas, nas gravações. Na fase de desenvolvimento foi reconstruída a elaboração da história e criado o roteiro do vídeo. Posteriormente foram realizadas as filmagens das cenas descritas no roteiro nas dependências da Utin do HUSM. Logo após ter todo o conteúdo audiovisual gravado, foi realizada a edição do material. Nas fases de implementação e avaliação o vídeo educativo foi analisado e avaliado pelo Núcleo de Educação Permanente em Saúde (Neps) e pelas enfermeiras da Utin do HUSM, com base no seu conteúdo, nos aspectos técnico-estéticos e na proposta pedagógica.

$\mathrm{Na}$ quarta etapa foi realizado o processo de validação do material por essas duas equipes do HUSM citadas anteriormente. Depois de exposto o vídeo às enfermeiras da Utin, foi realizada com estas uma entrevista gravada. Nesse momento da pesquisa 20 enfermeiras atuavam na Utin (uma a menos do que

Editora Unijuí - Revista Contexto \& Saúde - ISSN 2176-7114 - v. 21, n. 43, jul./set. 2021 
na segunda etapa), sendo todas estas convidadas a participar dessa etapa de validação do material. Após toda a análise do material coletado, junto com o parecer do Neps, o material foi apresentado em duas categorias, fundamentadas nos critérios que norteiam a produção de materiais educativos conforme Gomes (2008).

Durante toda a pesquisa foram respeitados todos os preceitos éticos fundamentais, baseando-se nas orientações e disposições da Resolução no 466/12 do Conselho Nacional de Saúde do Ministério da Saúde, em que estão regulamentadas as pesquisas envolvendo seres humanos (BRASIL, 2012).

\section{RESULTADOS E DISCUSSÃO}

Durante a pesquisa, na primeira fase da produção do vídeo, fase de análise, foram buscadas, por meio do questionário com as enfermeiras e entrevistas com as mães, informações que essas participantes acreditavam ser importantes que o material educativo a ser produzido contemplasse. Após a análise do material coletado, foram levantadas as necessidades das participantes, realizando-se um diagnóstico da situação. Elas deixaram sugestões, as quais foram agrupadas em temas centrais, conforme a Figura 1.

Figura 1 - Sugestões a partir do questionário aplicado às enfermeiras e da entrevista com as mães. Santa Maria, RS, 2020

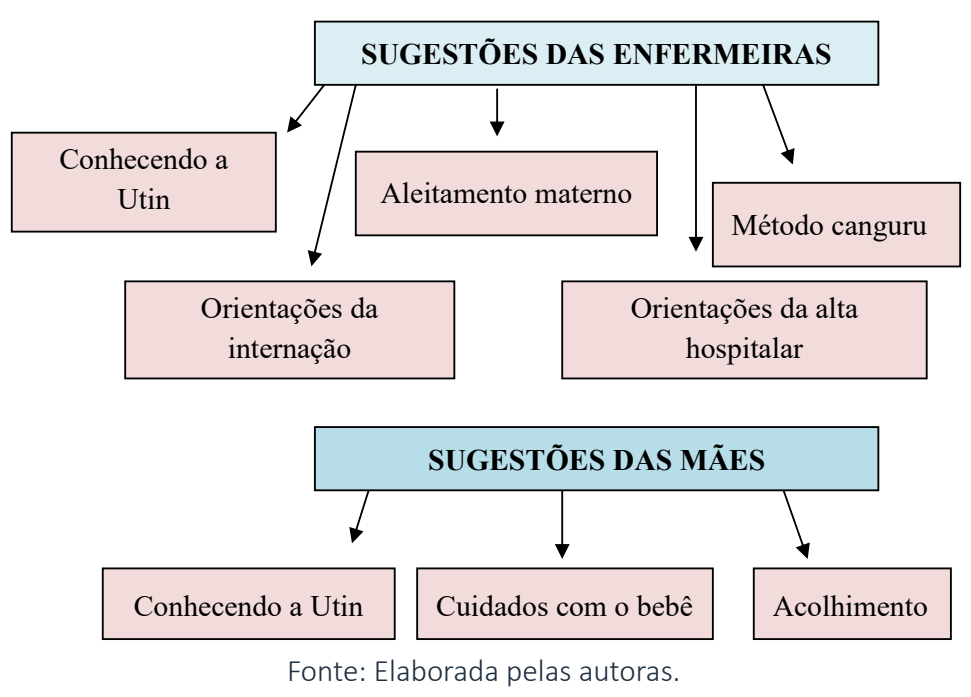

É de suma importância saber, portanto, o que os familiares dos RNs precisam nesse momento da hospitalização e, a partir daí, promover ações educativas, oferecendo suporte aos mesmos. Estratégias de educação em saúde são essenciais para o bom funcionamento dos serviços, tornando-os mais humanizados, acolhedores e com o olhar integral voltado ao paciente e sua família (SOUZA; PASSOS; SOUZA, 2019).

O cuidado é a essência da profissão na enfermagem. Neste estudo ele está voltado não somente ao neonato, mas, principalmente, à sua família. Pinto, Pettengill e Balieiro (2010, p. 135) acreditam que 
cuidar da família seja uma responsabilidade e compromisso moral do enfermeiro e para tanto é necessário que haja um ambiente de cuidado que favoreça o relacionamento entre enfermeiro-família, a fim de construir uma prática que a ajude no enfrentamento de dificuldades, em especial em situação de doença.

Conforme o grande número de internações neonatais e seu fator principal a prematuridade (FREITAS et al., 2018) -, o tempo de internação consiste em vários dias e até meses, com grandes riscos de complicações, pois os RNs não possuem ainda maturação fisiológica suficiente. Tornam-se necessárias, então, estratégias educativas para todo o tempo de hospitalização, proporcionando melhor humanização, minimizando o estresse e o anseio dos pais durante a permanência do RN na unidade, para que esse período seja o menos traumático possível e para que esses familiares se sintam acolhidos e possam aprender com o período de internação.

Acredita-se que realizar Educação em Saúde, mediada por tecnologias educativas, poderá ser uma possibilidade de melhorar o diálogo e a interação entre os profissionais e os familiares. Essa atividade proporciona que os pais se sintam mais tranquilos e confiantes na equipe de saúde que está prestando assistência de enfermagem ao seu filho, contribuindo para um melhor acolhimento dos pais na Utin.

O vídeo educativo produzido, enquanto tecnologia educativa, foi intitulado "Orientações para familiares de RNs internados na Utin do Hospital Universitário de Santa Maria" (Figura 2), e tem duração de 5 minutos e 48 segundos, incluindo-se os créditos, estando dentro do tempo previsto para vídeos com caráter educativo, a fim de que o público se mantenha atento ao conteúdo.

Figura 2 - Cenas do vídeo educativo para a Utin do HUSM. Santa Maria, RS, 2020

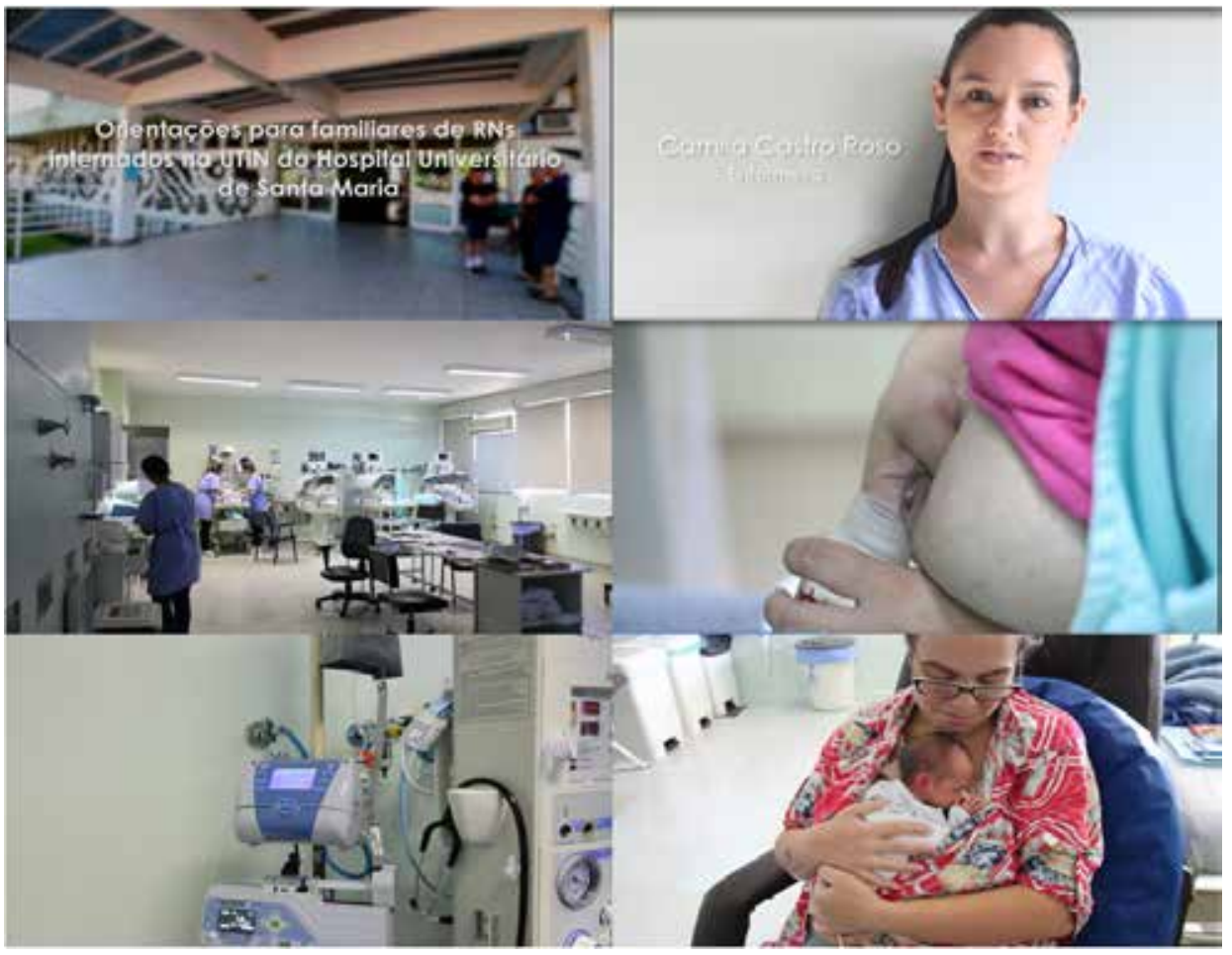

Fonte: Elaborada pelas autoras. 
Na quarta etapa da pesquisa o vídeo construído foi avaliado e validado por duas equipes que conhecem o trabalho realizado, sendo a do Neps e a de enfermeiras atuantes na Utin do HUSM. O Neps é representado por enfermeiras, uma pedagoga e uma psicóloga. Junto com uma jornalista e um design da Assessoria de Comunicação, fazem parte de uma Comissão Editorial, a qual analisa as produções de materiais. O material foi encaminhado para eles por e-mail, conforme solicitado. Avaliaram o vídeo por meio de reunião on-line e encaminharam seu parecer por e-mail, com as suas contribuições e sugestões.

Conforme as análises, a equipe do Neps relatou que o material ficou bem construído, com informações muito claras e objetivas. Destacou a iniciativa da produção desse tipo de material para realizar a educação em saúde na Utin, considerando-a inovadora, pois, até o momento, não existia nenhum recurso audiovisual para ser utilizado com os familiares dos RNs, contribuindo, assim, com o setor público.

A enfermagem pode atuar de forma criativa em suas atividades diárias, sempre buscando práticas inovadoras no seu ambiente de trabalho. Segundo Rosa et al. (2019):

\begin{abstract}
as práticas pedagógicas que despertem curiosidade e chamem a atenção dos interloctores, aliando o conhecimento científico e procedimentos técnicos em uma relação de ensino-aprendizagem, qualificam o cuidado prestado e resultam em processo terapêutico satisfatório. O vídeo educativo, enquanto uma tecnologia cuidativo-educacional fortalece a práxis da enfermagem e corrobora com novas perspectivas de intervenção que buscam a integralidade do cuidado, possibilitando a autonomia dos sujeitos e promovendo a qualidade de vida (p. 13).
\end{abstract}

Das 20 enfermeiras que trabalhavam no setor neonatal no momento da quarta etapa da pesquisa, todas foram convidadas a participar desta etapa do estudo e todas aceitaram. A enfermeira responsável pela unidade participou da produção do roteiro e atuou na gravação do vídeo como personagem principal, não participando, então, da avaliação do material, pois esteve envolvida diretamente na construção deste. Todas as outras 19 enfermeiras participaram do processo de avaliação e validação do vídeo.

Foi realizada entrevista semiestruturada com questões fechadas e abertas. As questões fechadas foram respondidas em uma tabela para serem avaliadas em cinco itens, organizadas conforme a escala de Likert.

Tabela 1 - Respostas das enfermeiras em relação aos critérios de avaliação/validação do vídeo. Santa Maria, RS, 2020

\begin{tabular}{l|c|c|c|c|c}
\hline \multicolumn{1}{c|}{ Critérios } & \multicolumn{5}{c}{ Enfermeiras (\%) } \\
\hline & CT & C & NCND & D & DT \\
\hline O conteúdo do vídeo é atualizado. & $19(100)$ & - & - & - & - \\
\hline $\begin{array}{l}\text { O conteúdo do material é transmitido de forma } \\
\text { clara. }\end{array}$ & $19(100)$ & - & - & - & - \\
\hline $\begin{array}{l}\text { O conteúdo do material é adequado aos pais, } \\
\text { de fácil entendimento para eles. }\end{array}$ & $18(95)$ & $1(5)$ & - & - & - \\
\hline
\end{tabular}

Editora Unijuí - Revista Contexto \& Saúde - ISSN 2176-7114 - v. 21, n. 43, jul./set. 2021 


\begin{tabular}{|c|c|c|c|c|c|}
\hline $\begin{array}{l}\text { A linguagem do vídeo é adequada, de fácil } \\
\text { entendimento para os pais. }\end{array}$ & $18(95)$ & $1(5)$ & - & - & - \\
\hline $\begin{array}{l}\text { Boa qualidade técnica e estética do som } \\
\text { ambiente. }\end{array}$ & $9(47)$ & $10(53)$ & - & - & - \\
\hline Duração do vídeo é adequada e suficiente. & $19(100)$ & - & - & - & - \\
\hline $\begin{array}{l}\text { A função do vídeo está claramente definida, } \\
\text { informando e sensibilizando os pais. }\end{array}$ & $19(100)$ & - & - & - & - \\
\hline As cenas são transmitidas de forma acolhedora. & $19(100)$ & - & - & - & - \\
\hline As ilustrações (imagens) são boas. & $19(100)$ & - & - & - & - \\
\hline $\begin{array}{l}\text { O uso de imagens reais ajuda no aprendizado } \\
\text { dos pais. }\end{array}$ & $19(100)$ & - & - & - & - \\
\hline $\begin{array}{l}\text { O vídeo apresenta dados de identificação dos } \\
\text { participantes (autores, instituição). }\end{array}$ & $18(95)$ & $1(5)$ & - & - & - \\
\hline O vídeo apresenta uma organização lógica. & $19(100)$ & - & - & - & - \\
\hline $\begin{array}{l}\text { O público do vídeo é claramente definido e } \\
\text { identificado. }\end{array}$ & $19(100)$ & - & - & - & - \\
\hline $\begin{array}{l}\text { O vídeo pode ser usado como ferramenta } \\
\text { educacional. }\end{array}$ & $19(100)$ & - & - & - & - \\
\hline
\end{tabular}

Abreviações: $\mathrm{CT}=$ Concordo Totalmente; $\mathrm{C}=$ Concordo; NCND = Não Concordo nem Discordo; $\mathrm{D}=$ Discordo; DT = Discordo Totalmente.

$$
\text { Fonte: Elaborada pelas autoras. }
$$

Os resultados apresentaram uma concordância de $100 \%$ quando se somam os conceitos de Concordo Totalmente e Concordo para cada critério estabelecido. A análise desses critérios da pesquisa foi de forma quantitativa, podendo ser realizada pelo cálculo de Índice de Validade de Conteúdo (IVC), que é calculado pelo somatório das participantes que concordaram, dividido pelo número de participantes e multiplicado por cem. Este método, muito utilizado na área da saúde, mede a proporção ou porcentagem dos participantes que estão em concordância sobre determinados critérios, permitindo que seja analisado cada critério individualmente e, depois, o instrumento como um todo (ROSA et al., 2019). Afirma-se, portanto, que o material proposto nesse instrumento se apresenta válido, com boa confiabilidade.

Após a leitura e análise das entrevistas das enfermeiras, junto com as contribuições fornecidas pelo Neps, o material é apresentado em duas categorias principais, expressando a percepção dos profissionais dessa área hospitalar em relação ao material construído: 1) Conteúdo, aspectos técnico-estéticos e proposta pedagógica do vídeo educativo; e 2) Tecnologia educativa como ferramenta na Educação em Saúde dos familiares. Essas categorias estão baseadas em itens elencados por Gomes (2008), que traz critérios utilizados na produção e análise de vídeos.

\section{Conteúdo, aspectos técnico-estéticos e proposta pedagógica do vídeo educativo}

A primeira categoria de análise do vídeo diz respeito à sua qualidade. Durante a entrevista foi questionada a opinião das enfermeiras participantes da pesquisa em relação ao vídeo que foi construído para ser utilizado por elas na Utin com os 
pais. Nessa categoria, é possível observar que todas gostaram do material, quando $84 \%$ (16) descreveram como excelente e $16 \%$ (3) como muito bom.

Achei excelente. Porque eu achei assim que ele ta mostrando toda a nossa realidade ali; quem tá de fora e quem tá chegando com o nenê consegue entender como é que funciona a Utin né, de que forma o seu filho vai ser atendido, tem todas as orientações, o funcionamento da unidade, a explicação dos equipamentos, que geralmente isso assusta (ENF 4).

Muito bom. Achei muito bom, bem esclarecedor, e mostra o dia a dia da UTI (ENF 11).

Conforme Rosa et al. (2019), os vídeos educativos não possuem a finalidade somente de propiciar novos conhecimentos, mas também de fortalecer os já existentes, auxiliando, ainda, os pacientes e os familiares de acordo com as suas necessidades. Neste contexto, os autores presumem que um material educativo, quando bem produzido e validado, pode contribuir modificando a realidade dos sujeitos a que se destina; no caso desta pesquisa, dos familiares dos RNs.

Foi realizada uma profunda reflexão na construção desse vídeo, baseando-se nos critérios que norteiam a produção de vídeos educativos, conforme Gomes (2008), a fim de organizar o material com uma linguagem simples e acessível a todos os pais, sem a utilização de linguagem técnica à qual os profissionais estão acostumados. Ao mesmo tempo, teve-se a preocupação de colocar todas as informações básicas do dia a dia da Utin atualizadas, apresentadas em uma organização lógica, com imagens reais para melhor acolhimento, em um vídeo de curta metragem para não ser cansativo e conseguir manter a atenção dos pais.

Bahia e Silva (2017) elencaram dez itens para concepção e produção de vídeos, dentre eles destacam-se a do vídeo ser o mais breve possível (buscar orientar e produzir vídeos com até oito minutos de duração) e ser um audiovisual (não deve estar pautado apenas na linguagem verbal, seja ela narrada ou escrita, deve-se explorar o som, imagem e movimento).

Em relação às informações que são compartilhadas com os pais, as enfermeiras (100\%) concordaram que o material está de acordo com as orientações que são fornecidas por elas durante o trabalho. Assim, o vídeo educativo produzido foi considerado um recurso complexo, bem construído, com todas as informações necessárias para os familiares que estão com seus filhos internados, sendo uma estratégia de comunicação de fundamental importância neste contexto.

Materiais educativos devem ser elaborados e avaliados muito bem antes de serem utilizados pela população-alvo. Esses materiais são mediadores do processo ensino-aprendizagem e têm sido largamente utilizados para a educação em saúde (LEITE et al., 2018). As enfermeiras relataram que com o vídeo os familiares entenderão melhor todo o funcionamento da unidade em que seus bebês estão hospitalizados de uma maneira mais didática, pois, além de ouvirem as explicações, estarão visualizando cada orientação nas imagens proporcionadas pelo vídeo.

Durante as entrevistas foi questionado às enfermeiras se gostariam de mudar algo no vídeo e solicitado que deixassem sugestões de aprimoramento para o mesmo. Os comentários e sugestões foram muito poucos. Foram delineados

Editora Unijuí - Revista Contexto \& Saúde - ISSN 2176-7114 - v. 21, n. 43, jul./set. 2021 
elogios em relação ao vídeo durante o momento da entrevista, parabenizando pelo trabalho, pela percepção de observar essa necessidade, por ser algo inovador no setor e que precisava para colaborar com o trabalho da equipe, ajudando no entendimento dos pais e melhorando o acolhimento deles na unidade, humanizando, assim, o cuidado do bebê e da sua família.

O comentário a seguir demonstra a satisfação e motivação com o material:

Eu acho uma ideia bem criativa, uma mudança pra melhor, é usar a tecnologia ao nosso favor, né, ilustrando, mostrando, acho que a gente tem que usar mais disso inclusive, pra que como profissionais também assim, entre nós, não só profissionais e pais, mas profissionais e equipe também assim. É uma coisa inovadora né. Porque os pais eles entram aqui e ficam ali naquele espaço, que é eles e o nenê sabe, e eles ficam bem limitados àquilo ali. Então, enxergando lá fora num todo, vai contribuir para uma melhora muito grande, assim, no comportamento deles com a equipe e com o nenê também. Acho que tu tá de parabéns, foi uma ideia bem inovadora, bem criativa. Que tem o seu devido reconhecimento, assim, porque a gente sabe que dá trabalho, é muito estudo e que a gente colha muitos bons frutos, assim, desse teu trabalho (ENF 7).

Em relação a sugestões/comentários de mudanças no vídeo, todas as enfermeiras disseram que não mudariam nada no conteúdo, pois estava bem completo, apenas deixaram algumas sugestões para contribuir no trabalho, reforçando que não faltaram informações. Assim, quanto ao conteúdo, baseado em Gomes (2008), o material apresenta uma qualidade científica, é atualizado, tem clareza, a linguagem é adequada ao público-alvo e a quantidade de informações é suficiente.

Conforme depoimento das enfermeiras, 53\% delas (10), como sugestões de melhorias, comentaram sobre o áudio do vídeo, que, em alguns momentos não era muito claro, ficando difícil de escutar em razão da música de fundo parecer ser muita alta e atrapalhar a fala da personagem. Duas enfermeiras (10\%) sugeriram mudar a cor da letra na parte onde aparecem as informações escritas no vídeo, pois a letra é branca no fundo azul, dificultando a visualização das informações. Esses critérios contemplam alguns dos aspectos técnico-estéticos na produção de vídeos, o que é evidenciado na voz das enfermeiras participantes:

Eu acho que não, não mudaria nada. Só a questão da música, que em alguns momentos a música fica alta para a fala da profissional que tá falando, mas no mais não, eu acho que tá bem objetivo, sucinto, assim, não tem de menos, não tem de mais, acho que tá ótimo, não pode ser uma coisa muito longa, que vai acabar se perdendo. Então eu acho que tá muito bom (ENF 9).

Não. Pensando assim agora, não. Só a questão da estética mesmo, a cor das letras (ENF 12).

Dentro do desenvolvimento de materiais educativos, destaca-se a importância do design instrucional, por ser uma área que colabora na definição de projetos, das estratégias e das tecnologias a serem utilizadas. No design, a ergonomia é fundamental, sendo uma área que apoia a produção de materiais, resultando em um produto de qualidade de acordo com os itens analisados. Neste contexto, segundo Batista (2008), as ações de percepção consideram principalmente o aspecto visual. Os códigos visuais fazem menção à definição, escolha ou

Editora Unijuí - Revista Contexto \& Saúde - ISSN 2176-7114 - v. 21, n. 43, jul./set. 2021 
especificação de cores das tipografias em diversos critérios, tais como o estilo, a estética-formal, as denotações e as conotações semióticas e mercadológicas.

A proposta pedagógica do material construído foi de apresentar as orientações da Utin para os pais de uma maneira acessível, de sensibilizá-los nesse momento da internação e de expor como funciona, na prática, a unidade de internação para melhor aprendizagem desses familiares, proporcionando mudanças de comportamento, de atitude ou de habilidade desse público-alvo diante do processo de hospitalização. Nessa proposta buscou-se compartilhar, por meio do vídeo, conteúdos de forma humanizada, de acordo com a realidade, para o público-alvo.

Durante a entrevista, uma das enfermeiras comentou que seria interessante, para dar continuidade a esse trabalho no futuro, produzir outro vídeo, em formato de documentário, com depoimentos de mães que já passaram pela Utin. Teve-se a intenção, durante o estudo, de desenvolver um vídeo abordando os depoimentos de mães, existindo até um roteiro pronto anexado na pesquisa, mas, devido ao momento vivido de pandemia pela Covid-19, não foi possível produzir esse outro material.

Outra sugestão foi de apenas uma enfermeira, mas muito relevante, que percebeu a falta no vídeo da parte da identificação do material, os logos da UFSM e do HUSM. Estes foram, então, acrescentados e também o da Empresa Brasileira de Serviços Hospitalares (EBSERH), ficando totalmente identificado, pois se o material é institucional é preciso aparecer todos os dados de identificação.

Após análise, avaliação e validação do material, os especialistas (Neps e enfermeiras) o consideraram de qualidade, atendendo os propósitos para o qual foi elaborado, sendo capaz de orientar os familiares, podendo ser utilizado pela equipe de enfermeiros no seu dia a dia com o público-alvo destinado, pois foi validado pelos especialistas, os quais atribuem qualidade ao material em termos de conteúdo e estética, pronto para ser disponibilizado aos familiares no hospital.

\section{Tecnologia educativa como ferramenta na Educação em Saúde dos familiares}

Em relação à tecnologia como ferramenta no contexto em tela, importa trazer que todas (100\%) as enfermeiras relataram que esta tecnologia educativa irá contribuir e muito na Educação em Saúde com esses familiares de várias maneiras, conforme é possível identificar na fala a seguir:

Pode contribuir bastante. Porque muitas vezes os pais estão bastante ansiosos quando os bebês internam né, então a gente orienta e essa orientação pra eles, no momento, eles não conseguem assimilar. Passando esse vídeo ali na sala de espera, eu acredito que vai ser um momento que eles estão mais tranquilos; é o momento que eles estão aguardando para verem o bebê deles, e eles vão conseguir assimilar melhor, vai ser de melhor entendimento pra eles (ENF 2).

Durante a entrevista com as enfermeiras, foram feitas indagações sobre se utilizariam esse vídeo educativo como apoio em sala de espera durante a educa-

Editora Unijuí - Revista Contexto \& Saúde - ISSN 2176-7114 - v. 21, n. 43, jul./set. 2021 
ção em saúde. Todas (100\%) responderam que sim, que utilizariam, fato identificado na fala seguinte:

Eu achei o vídeo muito didático, claro, eu acho que vai transmitir, tranquilizar os pais, como uma ferramenta educacional mesmo pra entrada desses pais que chegam bem angustiados; é muita coisa nova; além da doença do seu fiIho tem que tá preocupado conforme as rotinas, horários de visita, o que pode fazer, o que não pode fazer. Eu achei, assim, de uma ferramenta vital aqui pra UTI, que fazia muitos anos que já teria que ter um vídeo assim pra instruir os pais, achei muito claro, muito didático, com certeza vai ajudar muito no dia a dia (ENF 19).

Atualmente os vídeos educativos vêm sendo utilizados em todas as áreas, e a enfermagem, aos poucos, vem se apropriando dessas tecnologias como material de apoio, principalmente em atividades educativas. As tecnologias educativas audiovisuais apresentam-se como um interessante recurso a ser empregado para promover saúde, educação e aprendizado para quem as assistir.

Segundo Razera et al. (2014, p. 173), "a educação em saúde apoia-se em ações ou recursos de informação, educação e comunicação, podendo envolver materiais elaborados que têm como finalidade subsidiar essa interação". Os autores salientam que o vídeo educativo é uma das ferramentas de ensino que tem sido utilizada com maior frequência durante os últimos anos. Ainda informam que, para que se cumpra a sua finalidade, é necessário que quem o produza saiba selecionar e planejar o conteúdo necessário, considerando o seu público-alvo.

O vídeo educativo produzido neste estudo é relevante, pois se trata de uma tecnologia disponibilizada como veículo de comunicação e educação para os familiares. Para Freire, educação é comunicação, diálogo, e não transferência de saber, mas um encontro de sujeitos, que buscam a significação dos significados (apud FERNANDES; BACKES, 2010). Quanto aos vídeos, Tiellet (2010, p. 12) afirma que "o vídeo, como meio de comunicação visual dinâmico e combinado com o áudio, constitui-se num poderoso meio de comunicação". Assim, o vídeo poderá ser um importante meio de reforçar as informações fornecidas pelas enfermeiras durante o diálogo com os pais na Utin.

Observou-se, nos relatos das enfermeiras, que, às vezes, não se tem tempo suficiente para cuidar dos pais, de realizar a educação em saúde com eles de uma forma mais acolhedora. Sabe-se das individualidades que uma Utin proporciona, como o atendimento de pacientes em estado muito grave, que mobiliza bastante a equipe para os cuidados intensivos, a superlotação com leitos extras, e, por vezes, o número reduzido de funcionários. Realizar a educação em saúde com os pais dos pacientes, portanto, também depende das condições de trabaIho das profissionais.

Conforme as participantes relataram, o vídeo produzido nesta pesquisa vem para contribuir no setor como um material de apoio, ajudando a melhorar o processo de acolhimento. Precisa-se refletir sempre sobre como se pode proporcionar um bom acolhimento aos usuários da saúde. "O serviço é que precisa se organizar para oferecer o acolhimento, e não o contrário" (COUTINHO; BARBIERI; SANTOS, 2015, p. 522).

Editora Unijuí - Revista Contexto \& Saúde - ISSN 2176-7114 - v. 21, n. 43, jul./set. 2021 
Nietsche et al. (2012) deixam claro que a produção de tecnologias educativas nasce das necessidades que são percebidas nos serviços, da utilização do conhecimento do profissional e da criatividade também. Assim, para Barreiro (2016), ser criativo é a chave do sucesso, e o material deve transmitir a mensagem de maneira clara e com toque artístico, envolvendo o público de forma única.

Precisa-se pensar que, quando for produzido um material educativo, algumas pessoas não possuem acesso a informações e algumas apresentam dificuldade de entendimento. Assim, busca-se sempre produzir algo que contemple as necessidades dos usuários, numa perspectiva de equidade e integralidade. $\mathrm{Na}$ educação em saúde deve ser salientada a educação popular em saúde, quando são valorizados os saberes e o conhecimento prévio das pessoas e não somente o seu conhecimento científico (FALKENBERG et al., 2014).

Em relação ao acolhimento, para todas as entrevistadas foi questionado se o vídeo produzido proporcionaria ou não um melhor acolhimento aos futuros pais que assistirão o vídeo na sala de espera. Todas (100\%) responderam que proporcionará melhor acolhimento, ajudando-os a sentirem-se mais tranquilos nesse momento que estão vivendo, até por ser um material que foi produzido e dedicado a eles.

\begin{abstract}
Além do acolhimento que a gente faz aqui dentro, eu acho que seria um primeiro acolhimento, que é bem interessante. Eles achariam bem interessante e perceberiam também a nossa preocupação em acolher eles já desde o início, desde a porta pra fora. Antes deles entrar na Utin, eles já se sentem mais acoIhidos a partir desse vídeo; acho que vai ser bem positivo (ENF 8).

Com certeza sim, de uma maneira humanizada, e até por eles visualizarem a equipe, os equipamentos que a gente usa, a incubadora, porque tudo é muito novo pra eles né, e aí gera muita ansiedade (ENF 19).
\end{abstract}

Nesse contexto, as enfermeiras consideraram o vídeo acolhedor, pois abordou assuntos relacionados à Utin, à internação dos bebês, a quem cuida deles lá dentro, aos equipamentos que são utilizados, a como é o fluxo desde a internação até a alta hospitalar, às rotinas da unidade, além de ter sido gravado por uma enfermeira que trabalha no local e apresentado com uma linguagem de fácil entendimento. Segundo Rosa et al. (2019, p.12), "o conteúdo abordado em uma tecnologia audiovisual com potencial para sensibilizar o público-alvo necessita ser compreensível por qualquer pessoa, sendo claro em sua abordagem técnica e científica".

O acolhimento é conseguir reconhecer as necessidades dos familiares. O primeiro contato desses familiares com a Utin normalmente é marcado pelo desconhecido. Esse acolhimento precisa ser construído de forma coletiva, tendo como objetivo a construção de relações de confiança, de compromisso e de vínculo entre o trabalhador e o usuário (BRASIL, 2020). Assim, o acolhimento pretende humanizar os trabalhadores e os serviços de saúde com os seus usuários.

Por fim, este trabalho contribuirá para a área neonatal, para o hospital e toda a comunidade, e o enfermeiro pode atuar como mediador em suas práticas educativas junto aos familiares dentro da Utin, utilizando o vídeo educativo 
como um material de apoio durante as orientações de enfermagem. Ainda, oferece suporte emocional para que os pais possam viver essa hospitalização com menos sofrimento, proporcionando melhor acolhimento de forma humanizada.

Salienta-se que uma das limitações da pesquisa foi não conseguirmos avaliar/validar esse material com os familiares em razão da pandemia vivida no momento do coronavírus (Covid-19), o que acarretou na reorganização da pesquisa.

\section{CONSIDERAÇÕES FINAIS}

O enfermeiro, enquanto educador em saúde, precisa utilizar-se das tecnologias para elaborar seus materiais para que venha colaborar no processo de educação em saúde e melhorar o acolhimento dos familiares no contexto hospitalar. A fim de melhorar o entendimento dos pais em relação à hospitalização dos seus filhos, esta pesquisa produziu um vídeo educativo destinado a esses familiares a ser compartilhado em sala de espera.

Os resultados permitiram concluir que o vídeo construído foi validado pelos especialistas da área hospitalar, sendo um material produzido e direcionado a ajudar os familiares a entender melhor todo o processo de internação, meIhorando, assim, o acolhimento deles nesse setor crítico, em que se encontram frágeis e sensíveis no momento.

Esta tecnologia educativa poderá ser utilizada como uma ferramenta de estratégia na educação em saúde pela enfermagem da Utin junto aos familiares dos RNs, a qual mediará o cuidar-educando em várias situações do seu dia a dia. É um material de caráter inovador, produzido dentro de um hospital público, contando com a parceria do Neps e das enfermeiras atuantes no setor. Considera-se sua viabilidade pelo seu conteúdo estar de acordo com a literatura e estar baseado nas necessidades destacadas pelas mães e enfermeiras durante as coletas de dados.

Percebe-se, ainda, um número reduzido de estudos e pesquisas apoiando os familiares em Utin. Espera-se que este estudo possa incentivar a realização de outros trabalhos nessa área, abrindo possibilidades futuras, buscando sempre um melhor acolhimento dos familiares dentro do hospital público de saúde, cumprindo com uma das diretrizes da Política Nacional de Humanização do Ministério da Saúde.

\section{REFERÊNCIAS}

BAHIA, A. B.; SILVA, A. R. L. Modelo de produção de vídeo didático para Ead. Novas Tecnologias na Educação, v. 15, n. 1, p. 1-10, jul. 2017. Disponível em: https://seer.ufrgs.br/ renote/article/view/75116. Acesso em: 5 set. 2019.

BARDIN, L. Análise de conteúdos. São Paulo: Edições 70, 2016.

BARREIRO, R. M. C. Um breve panorama sobre o design instrucional. EAD EM FOCO, v. 6, n. 2, p. 61-75, ago. 2016. Disponível em: http://eademfoco.cecierj.edu.br/index.php/ Revista/article/view/375. Acesso em: 10 mar. 2019.

BATISTA, M. L. F. S. Design instrucional: uma abordagem do design gráfico para o desenvolvimento de ferramentas de suporte à Educação a Distância. 2008. Dissertação (Mestrado em Design) - Universidade Estadual Paulista. Faculdade de Arquitetura, Artes e

Editora Unijuí - Revista Contexto \& Saúde - ISSN 2176-7114 - v. 21, n. 43, jul./set. 2021 
Comunicação, São Paulo, 2008. Disponível em: https://repositorio.unesp.br/bitstream/ handle/11449/89714/batista_mlfs_me_bauru.pdf?sequence=1\&isAllowed=y. Acesso em: 7 abr. 2020.

BRASIL. Ministério da Saúde. Resolução no 466, de 12 de dezembro de 2012. Dispõe sobre as diretrizes e as normas regulamentadoras de pesquisa envolvendo seres humanos. Conselho Nacional de Saúde. Brasília: Editora Ministério da Saúde, 2012. 12 p. Disponível em: http://conselho.saude.gov.br/resolucoes/2012/reso466.pdf. Acesso em: 20 nov. 2018.

BRASIL. Informações Ministério da Saúde. Brasília: Ministério da saúde, 2020. Disponível em: http://portalms.saude.gov.br/. Acesso em: 5 abr. 2020.

COUTINHO, L. R. P.; BARBIERI, A. R.; SANTOS, M. L. M. Acolhimento na atenção primária à saúde: revisão integrativa. Revista Saúde Debate, v. 39, n. 105, p. 514-524, 2015. Disponível em: https://www.scielo.br/pdf/sdeb/v39n105/0103-1104-sdeb-39-105-00514.pdf. Acesso em: 29 abr. 2020.

FALKENBERG, M. B. et al. Educação em saúde e educação na saúde: conceitos e implicações para a saúde coletiva. Revista Ciência e Saúde Coletiva, v. 19, n. 3, p. 847-852, 2014. Disponível em: https://www.scielo.br/pdf/csc/v19n3/1413-8123-csc-19-03-00847.pdf. Acesso em: 24 jun. 2020.

FERNANDES, M. C. P.; BACKES, V. M. S. Educação em saúde: perspectivas de uma equipe da Estratégia Saúde da Família sob a óptica de Paulo Freire. Revista Brasileira de Enfermagem, Brasília, v. 63, n. 4, p. 567-573, 2010. Disponível em: https://www.scielo.br/pdf/ reben/v63n4/11.pdf. Acesso em: 22 set. 2020.

FILATRO, A. Design instrucional na prática. São Paulo: Pearson, 2008.

FONTANELLA, B. J. B.; RICAS, J.; TURATO, E. R. Amostragem por saturação em pesquisas qualitativas em saúde: contribuições teóricas. Caderno de Saúde Pública, v. 24, n. 1, p. 17-27, 2008. Disponível em: http://www.scielo.br/pdf/csp/v24n1/02.pdf. Acesso em: 5 jan. 2019.

FREITAS, M. C. N. et al. Caracterização dos recém-nascidos internados em Unidade de Terapia Intensiva. Revista Multidisciplinar e de Psicologia, v. 12, n. 40, p. 228-242, 2018. Disponível em: https://idonline.emnuvens.com.br/id/article/view/1110/1619. Acesso em: 12 mar. 2019.

GOMES, L. F. Vídeos didáticos: uma proposta de critérios para análise. Revista Brasileira Estudos Pedagógicos, Brasília, v. 89, n. 223, p. 477-492, 2008. Disponível em: http://www. emaberto.inep.gov.br/index.php/rbep/article/view/688/666. Acesso em: 16 jul. 2019.

LANDEIRO, M. J. L. et al. Tecnologia educacional na gestão de cuidados: perfil tecnológico de enfermeiros de hospitais portugueses. Revista Escola de Enfermagem da USP, v. 49, n. 2, p. 150-55, 2015. Disponível em: http://www.scielo.br/pdf/reeusp/v49nspe2/ 1980-220X-reeusp-49-spe2-0150.pdf. Acesso em: 10 out. 2018.

LEITE, S. S. et al. Construção e validação de instrumento de validação de conteúdo educativo em saúde. Revista Brasileira Enfermagem, v. 71, n. 4, p. 1.732-1.738, 2018. Disponível em: https://periodicos.ufpe.br/revistas/revistaenfermagem/article/view/238588/31387. Acesso em: 29 abr. 2020.

NIETSCHE, E. A. et al. Tecnologias inovadoras do cuidado em enfermagem. Revista de Enfermagem UFSM, v. 2, n. 1, p. 182-189, 2012. Disponível em: file://D:/Usu\%C3\%A1rio/ Downloads/3591-22992-1-PB.pdf. Acesso em: 20 out. 2018.

PINTO, J. P.; PETTENGILL, M. M.; BALIEIRO, M. M. F. G. Cuidado centrado na família e sua aplicação na enfermagem pediátrica. Revista Brasileira de Enfermagem, Brasília, v. 63, n. 1, p. 132-135, 2010. Disponível em: https://www.scielo.br/pdf/reben/v63n1/v63n1a22. pdf. Acesso em: 6 abr. 2020.

RAZERA, A. P. R. et al. Vídeo educativo: estratégia de ensino-aprendizagem para pacientes em tratamento quimioterápico. Revista Ciência e Cuidado em Saúde, v. 13, n. 1, p. 173-178, 2014. Disponível em: http://www.periodicos.uem.br/ojs/index.php/CiencCuidSaude/article/view/19659/pdf_156. Acesso em: 28 abr. 2020.

ROSA, B. V. C. et al. Desenvolvimento e validação de tecnologia educativa audiovisual para famílias e pessoas com colostomia por câncer. Revista Texto Contexto Enfermagem,

Editora Unijuí - Revista Contexto \& Saúde - ISSN 2176-7114 - v. 21, n. 43, jul./set. 2021 
v. 28, p. 1-15, 2019. Disponível em: http://www.scielo.br/pdf/tce/v28/pt_1980-265X-tce-28-e20180053.pdf. Acesso em: 28 abr. 2020.

SOMBRIO, G. S.; ULBRICHT, V. R. Tecnologias emergentes como possibilidade de inovação na educação. Revista Latino-Americana de Inovação e Engenharia de Produção, v. 3, n. 4, p. 63-73, 2015. Disponível em: https://revistas.ufpr.br/relainep/article/view/43603. Acesso em: 21 mar. 2019.

SOUSA, F. C. P. et al. A participação da família na segurança do paciente em unidades neonatais na perspectiva do enfermeiro. Revista Texto Contexto Enfermagem, v. 26, n. 3, 2017. Disponível em: http://www.scielo.br/scielo.php?pi$d=$ S0104-07072017000300314\&script=sci_abstract\&tlng=pt. Acesso em: 17 set. 2019.

SOUZA, I. V. B. et al. Educação em saúde e enfermagem: revisão integrativa da literatura. Revista Ciência Saúde Nova Esperança, v. 11, n. 1, p. 112-121, 2013. Disponível em: http://www.facene.com.br/wp-content/uploads/2010/11/Educa\%E2\%94\%9C\%C2\%BA\%E2 \%94 \%9C\%C3\%BAo-em-sa\%E2\%94\%9C\%E2\%95\%91de-e-enfermagem.pdf. Acesso em: 15 ago. 2020.

SOUZA, D. C. M.; PASSOS, R. C.; SOUZA, B. C. C. Educação em saúde para familiares de recém-nascidos em UTI, pós-alta e follow-up. Revista Cient. da Saúde, Rio de Janeiro, v. 4, n. 2, p. 26-49, 2019. Disponível em: https://smsrio.orgsrevistasindex.phpsrevasarticles download. Acesso em: 6 dez. 2019.

TIELLET, C. A. B. Construção e avaliação do hipervídeo como ferramenta auxiliar para aprendizagem de cirurgia. 2010. Tese (Doutorado em Informática na Educação) - Universidade Federal do Rio Grande do Sul, UFRGS, Porto Alegre, 2010. 